\title{
Muscle strength and bone mass density in haemodialysis patients
}

\author{
DOI: https://doi.org/10.5114/pq.2019.83436
}

\author{
Tadeusz Fiłon', Łukasz Rogowski², Mariusz Kusztal ${ }^{3}$, Katarzyna Bulińska ${ }^{4}$, Weronika Pawlaczyk ${ }^{4}$, \\ Tomasz Gołębiowski ${ }^{3}$, Agnieszka Zembroń-Łacny ${ }^{5}$, Marian Klinger ${ }^{3}$, Marek Woźniewski ${ }^{4}$, Wioletta Dziubek ${ }^{4}$ \\ ${ }^{1}$ Rennes Health and Rehab Center, Peshtigo, USA \\ 2 Nonpublic Medical College in Wroclaw, Wrocław, Poland \\ ${ }^{3}$ Department and Clinic of Nephrology and Transplantation Medicine, Wroclaw Medical University, Wrocław, Poland \\ ${ }^{4}$ Department of Physiotherapy, University School of Physical Education in Wroclaw, Wrocław, Poland \\ ${ }^{5}$ Department of Biological Basis of Sport, University of Zielona Góra, Zielona Góra, Poland
}

\section{Abstract}

Introduction. The aim of the study was to examine muscle strength and bone density in patients with end stage renal disease on maintenance haemodialysis.

Methods. The study included 76 patients: 29 women and 47 men aged 42-90 years. The time on dialysis varied from 2 months to 13 years. Bone density was assessed with the dual-energy X-ray absorptiometry method, and muscle strength of upper and lower extremities with Rikli and Jones arm curl test and the 30-second sit-to-stand test.

Results. Significant correlations between muscle strength and bone density were found. Results varied in relation to gender. A higher rate of upper extremity muscle strength loss was noted among men. A higher rate of lower extremity muscle strength loss was observed in the female group. A higher rate of bone density loss was reported among women than in men.

Conclusions. The relationship between muscle strength and bone mass density among haemodialysis patients warrants further study to clarify if physical exercise focused on muscle in those patients can improve bone mass density.

Key words: muscle strength, bone mass density, end stage renal disease (ESRD), haemodialysis

\section{Introduction}

Besides cardio-vascular diseases, chronic kidney disease is considered one of the biggest global health challenges of the $21^{\text {st }}$ century. Haemodialysis is the most common treatment of end stage renal disease (ESRD) globally and is applied in $93 \%$ of cases in Poland [1].

High incidence of chronic kidney disease is related to cardio-vascular diseases, the increasing life expectancy, and low level of physical activity. The progressive nature of the disease secondarily causes limitations of physical fitness and dialysis becomes another factor leading to its deterioration [2, 3].

The dialysis patients population are less active, have low activity tolerance, and demonstrate lower functional level comparing with the general population. The decline in function is associated with low quality of life and high mortality $[4,5]$.

The main, yet unavoidable causes of physical fitness decline are the prolonged immobility due to the long duration of dialysis sessions (4-6 hours) and the frequency of therapy (2-3 times a week), delivered in a sitting or supine position. In a one-year perspective, it aggregates to 400-900 hours of immobility. In addition, the significantly lowered level of physical fitness follows the impaired muscle function related to uremic myopathy [6-8].

All the above changes result in a deterioration of muscle strength and endurance, impaired performance in dynamic activities leading to decline in the activities of daily living, increased fall risk, loss of independence, and increased mortality $[9,10]$.
Patients undergoing haemodialysis develop various musculoskeletal complications, mainly due to renal osteodystrophy [11-13]. Renal osteodystrophy is defined by decreased synthesis of $1,25(\mathrm{OH})_{2} \mathrm{D}$ vitamin, hypersensitivity to parathyroid hormone, decreased calcium absorption, hyperphosphatemia, and increased aluminum deposits in the bone structure. Patients with osteodystrophy demonstrate bone demineralization [14].

The chronic kidney disease-related decrease of bone mineral density (BMD) may lead to increased risk of bone fractures. Age, postmenopausal status, sedentary lifestyle, older type corticosteroid treatment, and haemodialysis may expose patients to higher risk of osteoporosis. However, there is not enough evidence supporting the possible effects of these factors [12, 15-17].

Muscle strength seems to decline with age more than muscle mass. Furthermore, muscle strength loss may not be related to muscle mass. The correlation between muscle strength and muscle mass is not linear. Muscle strength loss is significantly greater, especially in individuals over 70 years of age, which indirectly suggests that general muscle loss might be correlated with bone degeneration. Inactivity may be one of the possible reasons for poor muscle strength and muscle mass loss at all ages [15, 18].

On the other hand, it has been established that people with weak bones have tendencies to decreased physical activity. It has been known that the aging process is characterized by a progressive decline of muscle strength, muscle mass, balance, and mobility; therefore, muscle strength might be considered as independent factor of bone degeneration

Correspondence address: Wioletta Dziubek, Department of Physiotherapy, University School of Physical Education in Wroclaw, al. I.J. Paderewskiego 35, 51-612 Wrocław, Poland, e-mail: wioletta.dziubek@awf.wroc.pl

Received: 23.11.2018

Accepted: 04.03.2019

Citation: Fiłon T, Rogowski L, Kusztal M, Bulińska K, Pawlaczyk W, Gołębiowski T, Zembroń-Łacny A, Klinger M, Woźniewski M, Dziubek W. Muscle strength and bone mass density in haemodialysis patients. Physiother Quart. 2019;27(1):39-45; doi: https://doi.org/10.5114/pq.2019.83436. 
risk. Routine exercise improves skeletal integrity and muscle efficiency, and can decrease the risk of bone fractures [14, $18,19]$.

The aim of this study was to assess muscle strength and bone mass density in patients with ESRD and to determine if the duration of dialysis therapy interferes with these measures. The secondary aim was to evaluate the influence of non-modifiable factors (gender, age, comorbidities) on BMD and muscle strength.

\section{Subjects and methods}

\section{Participants}

Overall, 76 patients, including 29 women (38\%), were recruited into the study. All participants were stable patients with ESRD on maintenance haemodialysis qualified to the study by a nephrologist.

Exclusion criteria were as follows:

- medical contraindications to participate in physical testing;

- disability preventing performance in or completion of physical testing;

- lack of patient consent.

The study was performed in the University Clinical Hospital in Wrocław.

\section{Methods}

\section{Assessment of upper and lower extremities muscle strength}

Muscle strength was assessed with two trials of Rikli and Jones test: arm curl test (upper extremity strength) and 30-second sit-to-stand test (lower extremity strength).

\section{Arm curl test}

- The subject sits in a 43.18-cm high chair without armrest and straight back, feet flat on the floor.

- In the dominant hand (for dialysis patients, the arm without the fistula port), the subject holds a dumbbell of $5 \mathrm{lbs}(2.27 \mathrm{~kg})$ for women or $8 \mathrm{lbs}(3.63 \mathrm{~kg})$ for men.

- The subject's arm is pointing down next to the chair, perpendicular to the floor, with the hand in suitcase grip and palm facing towards the body.

- On the administrator's start command, the subject performs elbow flexion with forearm supination and returns to the initial position, repeatedly for a total of 30 seconds.

- The administrator controls appropriate test performance by stabilizing the subject's arm with fingers in the middle of the biceps, also assuring elbow full flexion and extension [20].

The test assesses functional upper body strength associated with functional activities, including lifting, carrying, and housekeeping. The score is the total number of controlled arm curls performed in 30 seconds. 'Risk zone' subjects perform less than 11 repetitions [21].

\section{0-second sit-to-stand test}

- The height of the chair and the sitting position the same as in the previous test.

- Arms crossed and held against the chest.

- On the administrator's start command, the subject stands up from the chair and then returns to the initial sitting position.

- In 30 seconds, the subject attempts to perform as many is still standing, a full repetition is counted and added to the final score [20].

The test assesses functional lower body strength associated with functional activities, including stair climbing, getting up from a chair or tub, and car transfers. The test is also used to evaluate the risk of falls. The score is the number of correctly performed repetitions in 30 seconds' time. 'Risk zone' subjects perform less than 8 repetitions [21].

Before and after the tests, hemodynamic parameters were measured: blood pressure and heart rate, in accordance with the Senior Fitness Test protocol [20-22].

\section{Bone mineral density assessment}

Bone density was measured with dual-energy X-ray absorptiometry (DXA) of femoral neck.

\section{Statistical analysis}

The statistical analysis of the studied group involved determining the mean variables and standard deviation of linear variables. On the basis of the minimal and maximal variables, the range of variability was determined. The Pearson linear correlation coefficient $(r)$ was used to analyse the correlation of linear variables. The chi-square independence test served to determine the correlation of categorical variables. The differences of linear variables between men and women were evaluated with the Student test for independent samples, and the significance of the studied variable changes were assessed with the Student test for dependent samples. To compare 3 mean variables (3 bone density categories), one-way analysis of variance (ANOVA) was utilized. The result of the variance analysis did not require the use of a posthoc test. The significance level was analysed with the use of the critical value of $p<0.05$. The analysis was performed with the Statistica 12 software from StatSoft company.

\section{Ethical approval}

The research related to human use has been complied with all the relevant national regulations and institutional policies, has followed the tenets of the Declaration of Helsinki, and has been approved by the Ethics Committee (18.01.2012) of the University School of Physical Education in Wroclaw. The study was performed within a project of the National Science Centre in Poland, grant No. 2011/03/B/NZ7/01764. The trial was registered in the Australian New Zealand Clinical Trials Registry (ACTRN 12618001870246).

\section{Informed consent}

Informed consent has been obtained from all individuals included in this study.

\section{Results}

The demographic and clinical characteristics of the participants are summarized in Table 1. The subjects' age ranged from 42 to 90 years (average age: $64.2 \pm 10.7$ years). Men had higher values of height and weight in comparison with women. Years of dialysis in the studied population ranged from 2 to 13 years, with an average of 6.8 years. The average time of dialysis in women was significantly longer than in men.

Among the studied population, osteopenia or osteoporosis occurred in 35 subjects ( $46 \%$ of the studied group). Cases of osteoporosis were confirmed only in women. Also, cases of osteopenia were more prevalent in that group (Table 2).

The results of densitometry (T-score and Z-score) indicate a significant correlation with the number of years on 
Table 1. Demographic and clinical characteristics of the study patients

\begin{tabular}{|l|c|c|c|c|}
\hline \multirow{2}{*}{ Variable } & Women $(n=29)$ & Men $(n=47)$ & $t$ & $p$ \\
\cline { 2 - 5 } & mean $\pm S D$ & mean $\pm S D$ & 0.013 & 0.990 \\
\hline Age (years) & $64.1 \pm 9.5$ & $64.2 \pm 11.4$ & 10.22 & $<0.001$ \\
\hline Height $(\mathrm{cm})$ & $159.7 \pm 5.7$ & $174.3 \pm 6.3$ & 7.13 & $<0.001$ \\
\hline Weight $(\mathrm{kg})$ & $63.2 \pm 12.2$ & $81.9 \pm 10.4$ & 2.30 & 0.024 \\
\hline BMI & $24.8 \pm 4.7$ & $27.0 \pm 3.7$ & 3.137 & 0.002 \\
\hline Years on dialysis & $8.3 \pm 3.4$ & $5.9 \pm 3.2$ & & \multicolumn{2}{|c|}{ Student test } \\
\hline
\end{tabular}

$\mathrm{BMI}$ - body mass index

Table 2. Bone density, upper and lower extremity strength, and T-score and Z-score by gender

\begin{tabular}{|c|c|c|c|c|}
\hline \multirow{2}{*}{ Variable } & \multirow{2}{*}{ Women $(n=29)$} & \multirow{2}{*}{ Men $(n=47)$} & \multicolumn{2}{|c|}{ Student test } \\
\hline & & & $t$ & $p$ \\
\hline \multicolumn{5}{|l|}{ Bone density (WHO classification), $\mathrm{n}(\%)$} \\
\hline Normal & $10(34)$ & $31(66)$ & & \\
\hline Osteopenia & $11(38)$ & $16(34)$ & & \\
\hline Osteoporosis & $8(28)$ & $0(0)$ & & \\
\hline Lower extremity muscle strength ( 30 -second sit-to-stand test) & $12.2 \pm 4.3$ & $12.9 \pm 4.2$ & 0.68 & 0.4970 \\
\hline Upper extremity muscle strength (arm curl test) & $13.2 \pm 5.1$ & $16.3 \pm 5.1$ & 2.52 & 0.0140 \\
\hline T-score & $-1.68 \pm 1.42$ & $-0.72 \pm 0.83$ & 3.70 & 0.0004 \\
\hline Z-score & $-0.55 \pm 1.54$ & $-0.30 \pm 0.86$ & 0.91 & 0.3671 \\
\hline
\end{tabular}

dialysis treatment. Subjects with longer history of dialysis demonstrated lower bone density (Figure 1).

The number of comorbidities ranged between 1 and 6 in the studied group. The average number of comorbidities was 2.4 in women and 2.5 in men. The distribution of comorbidities is illustrated in Figure 2.

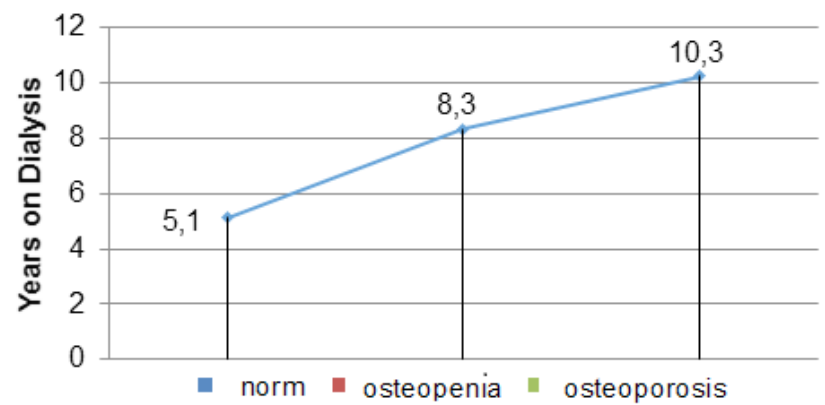

Figure 1. Correlation of bone density classification and number of years on dialysis

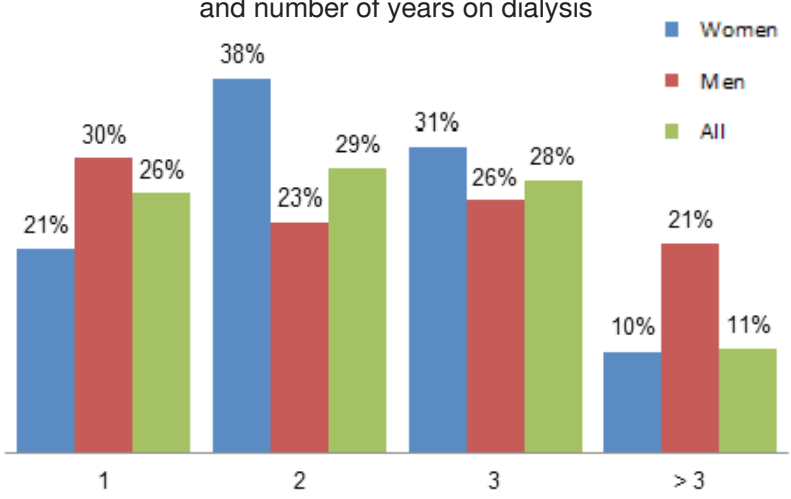

Number of Comorbidities

Figure 2. Distribution of comorbidities in the studied group

\section{Extremity muscle strength}

Extremity muscle strength was assessed with two trials of the Senior Fitness Test: 30-second sit-to-stand test (lower extremity muscle strength) and arm curl test (upper extremity muscle strength). Men demonstrated a significantly higher average level of upper extremity muscle strength than women but the average level of lower extremity muscle strength (average score of the 30-second sit-to-stand test) was not significantly different between the genders. Significant differences between men and women were observed in the average values of T-score but differences indicated by Z-score proved to be statistically insignificant (Table 2).

The average results of the 30-second sit-to-stand and arm curl tests were the highest in the group with normal bone density and the lowest in the group with osteoporosis. The tendency was specifically clear with respect to upper extremities. The ANOVA results did not allow for a statistical confirmation of correlation significance between the observed factors $(p>0.05)$ (Table 3 ).

The value of body mass index (BMI) scale indicates a significant negative correlation with the results of the 30-second sit-to-stand test in men. The BMI indicator significantly correlated with T-score in women. Among men, the correlation between BMI and T-score was weak and statistically insignificant. In the female group, the number of years on dialysis negatively correlated with the arm curl test results. In the male group, a significant negative correlation between the number of years on dialysis and lower extremity strength was established, while the number of years on dialysis practically did not correlate with upper extremity strength in the same group. The number of years on dialysis showed a significant negative correlation with T-score in both women 
Table 3. Correlation of the 30-second sit-to-stand test and arm curl test results and the level of bone density

\begin{tabular}{|c|c|c|c|c|c|}
\hline \multirow{2}{*}{ Test } & \multirow{2}{*}{ Bone density } & \multirow{2}{*}{ Mean } & \multirow{2}{*}{$S D$} & \multicolumn{2}{|c|}{ ANOVA } \\
\hline & & & & $F$ & $p$ \\
\hline \multirow{3}{*}{30 -second sit-to-stand } & norm & 12.7 & 3.2 & \multirow{3}{*}{0.03} & \multirow{3}{*}{0.97} \\
\hline & osteopenia & 12.6 & 5.5 & & \\
\hline & osteoporosis & 12.4 & 4.6 & & \\
\hline \multirow{3}{*}{ Arm curl } & norm & 15.9 & 4.8 & \multirow{3}{*}{1.38} & \multirow{3}{*}{0.257} \\
\hline & osteopenia & 14.6 & 6.0 & & \\
\hline & osteoporosis & 12.8 & 4.8 & & \\
\hline
\end{tabular}

Table 4. Pearson linear correlation between the 30-second sit-to-stand and arm curl test results and T-score, and BMI, number of years on dialysis, number of comorbidities, and age

\begin{tabular}{|l|c|c|c|c|}
\hline Correlating variable $(r$-Pearson) & Group & 30 -second sit-to-stand & Arm curl & T-score \\
\hline \multirow{4}{*}{ BMI } & women & -0.13 & 0.18 & $0.65^{*}$ \\
\cline { 2 - 5 } & men & $-0.42^{*}$ & -0.09 & 0.09 \\
\cline { 2 - 5 } & all & $-0.26^{*}$ & 0.09 & $0.46^{*}$ \\
\cline { 2 - 5 } Number of years on dialysis & women & -0.32 & $-0.43^{*}$ & $-0.51^{*}$ \\
\cline { 2 - 5 } & men & $-0.29^{*}$ & -0.03 & $-0.48^{*}$ \\
\cline { 2 - 5 } & all & $-0.31^{*}$ & $-0.26^{*}$ & $-0.55^{*}$ \\
\cline { 2 - 5 } & women & -0.13 & -0.20 & 0.12 \\
\cline { 2 - 5 } & men & -0.26 & -0.15 & -0.25 \\
\hline \multirow{3}{*}{ Age } & all & -0.21 & -0.15 & -0.05 \\
\cline { 2 - 5 } & women & $-0.50^{*}$ & $-0.42^{*}$ & 0.02 \\
\cline { 2 - 5 } & men & $-0.61^{*}$ & $-0.54^{*}$ & -0.12 \\
\hline
\end{tabular}

$* p<0.05$

Table 5. Blood pressure and heart rate changes after the performed physical tests

\begin{tabular}{|c|c|c|c|c|c|c|}
\hline \multirow{2}{*}{ Test } & \multirow{2}{*}{ Vital sign } & \multirow{2}{*}{$\begin{array}{l}\text { Before test } \\
\text { mean } \pm S D\end{array}$} & \multirow{2}{*}{$\begin{array}{c}\text { After test } \\
\text { mean } \pm S D\end{array}$} & \multirow{2}{*}{$\begin{array}{l}\text { Average } \\
\text { change }\end{array}$} & \multicolumn{2}{|c|}{ Student test } \\
\hline & & & & & $t$ & $p$ \\
\hline \multirow{3}{*}{ 30-second sit-to-stand } & systolic pressure (mm Hg) & $148.3 \pm 21.7$ & $150.9 \pm 23.8$ & 2.6 & 1.39 & 0.170 \\
\hline & diastolic pressure $(\mathrm{mm} \mathrm{Hg})$ & $85.5 \pm 14.8$ & $86.3 \pm 15.7$ & 0.8 & 0.54 & 0.590 \\
\hline & heart rate & $78.2 \pm 14.1$ & $86.2 \pm 15.4$ & 8.0 & 6.22 & $<0.001$ \\
\hline \multirow{3}{*}{ Arm curl } & systolic pressure (mm Hg) & $148.3 \pm 21.7$ & $151.0 \pm 22.2$ & 2.7 & 1.53 & 0.129 \\
\hline & diastolic pressure $(\mathrm{mm} \mathrm{Hg})$ & $85.5 \pm 14.8$ & $89.4 \pm 15.7$ & 3.8 & 2.58 & 0.012 \\
\hline & heart rate & $78.2 \pm 14.1$ & $82.2 \pm 14.9$ & 4.0 & 3.04 & 0.003 \\
\hline
\end{tabular}

Table 6. Pearson linear correlation between the subjects' age and blood pressure and heart rate changes after physical test performance

\begin{tabular}{|l|c|c|}
\hline \multirow{2}{*}{ Hemodynamic parameters } & \multicolumn{2}{|c|}{ Correlation of changes with age $(r$-Pearson) } \\
\cline { 2 - 3 } & After 30-second sit-to-stand & After arm curl \\
\hline Systolic blood pressure $(\mathrm{mm} \mathrm{Hg})$ & -0.16 & -0.03 \\
\hline Diastolic blood pressure $(\mathrm{mm} \mathrm{Hg})$ & 0.04 & -0.03 \\
\hline Heart rate & $-0.23^{*}$ & $-0.25^{*}$ \\
\hline
\end{tabular}


and men. No significant correlation was observed between the number of comorbidities and the results of both physical tests or T-score. The patients' age was negatively correlated with the results of both physical tests but showed no significant correlation with T-score (Table 4).

\section{Blood pressure and heart rate changes after activity}

The average values of blood pressure and heart rate increased after both physical test performances. The average increase of heart rate was statistically significant in both tests; in turn, the average increase of blood pressure was not statistically significant except diastolic pressure after the arm curl test (Table 5).

It was confirmed that the statistically significant change of heart rate value after both tests was also related to the subjects' age.

The age of patients significantly correlated with heart rate change after tests, but did not correlate with blood pressure changes (Table 6). The heart rate increase after the exercise tests was lower in older patients, which could reflect a lower intensity of exercise during testing in this age group.

\section{Discussion}

In recent years, interest in the effects of physical activity on the musculoskeletal system and the correlation between muscle strength and bone density has significantly increased $[15,16,18]$, with findings indicating that systematic physical activity leads to an increase of BMD. Those revelations are associated with Frost's theory of mechanical overload and its ability to improve bone modelling and arrangement [23].

In our study, women showed worse results of bone density than men. Osteoporosis and osteopenia as verified in the femoral neck DXA occurred more often in women. It is important to mention that women were longer on dialysis treatment than men, which suggests that the duration of dialysis therapy might significantly affect bone density (long lasting hyperparathyroidism as a frequent form of osteodystrophy).

In research performed by Riggs et al. [24] among over 250 subjects, loss of bone density did not exist until 50 years of age and after that accelerated between 51 and 65 years of age, slowing down after 65 years of age. The average BMD in subjects diagnosed with osteoporosis was lower than in healthy participants. Half of the healthy women at the age of 65 years and practically all women aged 85 years had significantly depleted bone density levels.

In the present study, bone density assessed on femoral neck was significantly lower in women than in men. In fact, the BMD results were most probably influenced by the significant difference in the time on dialysis between the gender groups. It looks like even older men who had been long on dialysis presented no osteoporosis - this might indicate that male gender is very protective against osteoporosis.

Bone histology assessed by Sherrard et al. [25] in patients on dialysis treatment was performed with the method of bone biopsy with quantitative histomorphometry. The results indicated an increased frequency of bone injury among the dialysis population (particularly in patients on peritoneal dialysis). It confirms that dialysis caused bone damage in all tested subjects.

The results of our study demonstrate a higher average strength of upper extremities in men with ESRD. The best results in both upper and lower extremity physical tests were achieved by subjects with normal bone density. The worst outcomes in both upper and lower extremity physical tests were obtained by subjects with osteoporosis, which confirms the correlation between muscle strength and bone density. A study carried out by Johansen et al. [26] showed that muscles of patients on dialysis were affected by significant atrophy and increased amount of inactive tissue. The correlation between muscle contraction area and muscle strength remains intact. Muscle atrophy is associated with poor physical condition. Therefore, enhanced physical activity or any other strategy to prevent atrophy can lead to increased bone density, decreased risk of bone fracture, and improved efficiency and quality of life.

In the current study, we presented a significant correlation between bone density and the results of muscle tests performed. The results of the 30-second sit-to-stand test did not differ significantly, but a difference between subjects with normal bone density who achieved the best test scores could be observed. The correlation of both physical test results with age was distinct and indicative of a decline of upper and lower extremity muscle strength with age.

Neuromuscular dysfunction is related to frequent lower extremity fractures in patients undergoing dialysis treatment [27]. Also, a study by Spindler et al. [28] confirmed a significant correlation between hip flexors, extensors and adductors muscle strength and bone density in the femoral neck and greater trochanter in both genders, although the difference in the presented study was insignificant. In turn, on the basis of the arm curl test results in this study, a significant correlation can be stated between upper extremity muscle strength and the level of bone degradation. A clear tendency of better test scores in relation to bone density can be observed as the average test score was 15.9 in subjects with normal bone density, 14.6 in those with osteopenia, and 12.8 in patients with osteoporosis.

The above described findings confirm the thesis that the muscle strength effect on bone density is much more prevalent in upper than lower extremities. Previous research performed by Floyd et al. [29] among chronic kidney disease patients indicates a myopathic nature of muscle strength loss as evidenced in quantitative electromyography. A part of the group demonstrated muscle dysfunction with associated serious bone complications. Administration of high doses of vitamin D provided significant improvement.

Johansen et al. [26] proved that subjects on dialysis were weaker and less active, and demonstrated lower walking speeds than random control group participants. The studied patients on dialysis developed significant muscular dystrophy.

A study performed by Nelson et al. [30] confirmed a positive effect of endurance exercise on maintaining bone density level in post-menopausal women, including an increase in muscle strength and decrease in the risk of bone fracture. However, if this effect can be observed in ESRD patients remains unproved.

According to a study by Stenvinkel et al. [31], one of the reasons for muscle strength loss is notorious malnutrition in patients with chronic kidney disease. These patients demonstrate lower body weight, limited energy reserve, noticeable loss of somatic protein, and associated low muscle mass. Various studies indicate signs of malnutrition in $23-76 \%$ of patients on dialysis.

In summary, the results of the current study confirm a correlation between muscle strength and bone density but also the effect of years on dialysis therapy on those parameters. Patients with impaired muscle strength have more problems with brittle bones. Frequent dialysis treatment is a forced im- 
mobilization, which limits physical activity, leading to muscle weakness.

Also, even in older men who had been long on dialysis, no osteoporosis was observed - this might indicate that male gender is very protective against osteoporosis.

We postulate that patients on dialysis should have exercise therapy applied because it can improve muscle strength and BMD and, presumably, lower the risk of bone fracture.

\section{Limitations}

A small number of haemodialysis patients and the lack of a control group (healthy people of the same age) are the limitations of the presented study.

\section{Conclusions}

1. Men demonstrated significantly higher average levels of upper extremity muscle strength than women, while this was not observed in lower extremities.

2. Cases of osteoporosis were confirmed only in the female group, in which osteopenia was also more frequent. The correlation of bone density and gender was statistically significant.

3. The average results of the 30 -second sit-to-stand and arm curl tests were the best in groups with normal bone density and the worst in groups with osteoporosis.

4. In both gender groups, the test results indicated a decrease of upper and lower extremity strength with age.

5. Long time on dialysis mainly weakened upper extremity muscles, with less effect on lower extremity muscles in women; in men, the effect was reversed, with increased weakening of lower extremity muscles and less impact on upper extremity muscles.

6. The results of densitometry (T-score and Z-score) presented a clear link with the number of years on dialysis. Patients with longer time on dialysis demonstrated lower bone density.

7. Comorbidities did not exert a significant effect on muscle strength in the studied subjects.

\section{Disclosure statement}

No author has any financial interest or received any financial benefit from this research.

\section{Conflict of interest}

The authors state no conflict of interest.

\section{References}

1. Rutkowski B. Home hemodialysis [in Polish]. Forum Nefrol. 2012;5(3):204-209.

2. ParmarMS. Chronic renal disease. BMJ.2002;325(7355): 85-90; doi: 10.1136/bmj.325.7355.85.

3. Baj Z, Zbróg Z, Szuflet A, Mańka S, Bartnicki P, Majewska E. Basic inflammatory indices and chosen neutrophil receptors expression in chronic haemodialysed patients. Centr Eur J Immunol. 2018;43(2):168-173; doi: 10.5114/ ceji.2018.77387.

4. Kouidi E, Albani M, Natsis K, Megalopoulos A, Gigis $P$, Guiba-Tziampiri $O$, et al. The effects of exercise training on muscle atrophy in haemodialysis patients. Nephrol Dial Transplant. 1998;13(3):685-699; doi: 10.1093/ndt/ 13.3.685.

5. Dziubek W, Bulińska K, Rogowski Ł, Gołębiowski T, Kusztal M, Grochola M, et al. The effects of aquatic exercises on physical fitness and muscle function in dialysis patients. Biomed Res Int. 2015:912980; doi: 10.1155/ 2015/912980.

6. Campistol JM. Uremic myopathy. Kidney Int. 2002; 62(5):1901-1913; doi: 10.1046/j.1523-1755.2002.00614.x.

7. Sakkas GK, Ball D, Mercer TH, Sargeant AJ, Tolfrey K, Naish PF. Atrophy of non-locomotor muscle in patients with end-stage renal failure. Nephrol Dial Transplant. 2003;18(10):2074-2081; doi: 10.1093/ndt/gfg325.

8. Gołębiowski T, Kusztal M, Weyde W, Dziubek W, Woźniewski M, Madziarska $\mathrm{K}$, et al. A program of physical rehabilitation during hemodialysis sessions improves the fitness of dialysis patients. Kidney Blood Press Res. 2012;35(4):290-296; doi: 10.1159/000335411.

9. Magnard J, Deschamps T, Cornu C, Paris A, Hristea D. Effects of a six-month intradialytic physical ACTIvity program and adequate NUTritional support on proteinenergy wasting, physical functioning and quality of life in chronic hemodialysis patients: ACTINUT study protocol for a randomised controlled trial. BMC Nephrol. 2013;14:259; doi: 10.1186/1471-2369-14-259.

10. Dziubek W, Bulińska K, Rogowski Ł, Kusztal M, Zembroń-Łacny A, Gołębiowski T, et al. Three-month endurance training improves functional fitness and knee muscle performance of patients with end stage renal disease (ESRD). Isokinet Exerc Sci. 2016;24(3):237-246; doi: 10.3233/IES-160623.

11. Polymeris A, Doumouchtsis K, Grapsa E. Bone mineral density and bone metabolism in hemodialysis patients. Correlation with PTH, 25OHD3 and leptin. Nefrologia. 2012;32(1):73-78; doi: 10.3265/Nefrologia.pre2011.

12. Bover J, Bailone L, López-Báez V, Benito S, Ciceri P, Galassi $A$, et al. Osteoporosis, bone mineral density and CKD-MBD: treatment considerations. J Nephrol. 2017; 30(5):677-687; doi: 10.1007/s40620-017-0404-z.

13. Najar MS, Mir MM, Muzamil M. Prevalence of osteoporosis in patients with chronic kidney disease (stages 3-5) in comparison with age- and sex-matched controls: a study from Kashmir Valley Tertiary Care Center. Saudi J Kidney Dis Transpl. 2017;28(3):538-544; doi: 10.4103/ 1319-2442.206439.

14. Wakasugi M, Kazama JJ, Taniguchi M, Wada A, Iseki K, Tsubakihara $Y$, et al. Increased risk of hip fracture among Japanese hemodialysis patients. J Bone Miner Metab. 2013;31(3):315-321; doi: 10.1007/s00774-012-0411-z.

15. Zhou Z, Zheng L, Wei D, Ye M, Li X. Muscular strength measurements indicate bone mineral density loss in postmenopausal women. Clin Interv Aging. 2013;8:14511459; doi: 10.2147/CIA.S48447.

16. Wilkinson TJ, Gould DW, Nixon DGD, Watson EL, Smith AC. Quality over quantity? Association of skeletal muscle myosteatosis and myofibrosis on physical function in chronic kidney disease. Nephrol Dial Transplant. 2018; doi: 10.1093/ndt/gfy139.

17. Nakanishi K, Shishido K, Kumata C, Ito K, Nakashima Y, Wakasa M. Bone density of the femoral neck in patients on maintenance dialysis. PLoS One. 2018;13(5): e0197965; doi: 10.1371/journal.pone.0197965.

18. Ma Y, Fu L, Jia L, Han P, Kang L, Yu H, et al. Muscle strength rather than muscle mass is associated with osteoporosis in older Chinese adults. J Formos Med Assoc. 2018;117(2):101-108; doi: 10.1016/j.jfma.2017. 03.004 .

19. Heinonen A, Kannus P, Sievänen H, Oja P, Pasanen M, Rinne M, et al. Randomised controlled trial of effect of high-impact exercise on selected risk factors for osteoporotic fractures. Lancet. 1996;348(9038):1343-1347; doi: 10.1016/S0140-6736(96)04214-6. 
20. Rikli RE, Jones CJ. Development and validation of a functional fitness test for community-residing older adults. J Aging Phys Act. 1999;7(2):129-161; doi: 10.1123/japa. 7.2.129.

21. Różańska-Kirschke $A$, Kocur $P$, Wilk $M$, Dylewicz $P$. The Fullerton test as an index of fitness in the elderly [in Polish]. Rehabil Med. 2006;10(2):15-19.

22. Langhammer B, Stanghelle JK. The Senior Fitness Test. J Physiother. 2015;61(3):163; doi: 10.1016/j.jphys.2015. 04.001.

23. Frost HM. Bone's mechanostat: a 2003 update. Anat Rec A Discov Mol Cell Evol Biol. 2003;275(2):1081-1101; doi: 10.1002/ar.a.10119.

24. Riggs BL, Melton LJ III, Robb RA, Camp JJ, Atkinson EJ, Peterson JM, et al. Population-based study of age and sex differences in bone volumetric density, size, geometry, and structure at different skeletal sites. J Bone Miner Res. 2004;19(12):1945-1954; doi: 10.1359/JBMR.040916.

25. Sherrard DJ, Hercz G, Pei Y, Maloney NA, Greenwood C, Manuel $A$, et al. The spectrum of bone disease in endstage renal failure - an evolving disorder. Kidney Int. 1993;43(2):436-442; doi: 10.1038/ki.1993.64.

26. Johansen KL, Shubert T, Doyle J, Soher B, Sakkas GK, Kent-Braun JA. Muscle atrophy in patients receiving hemodialysis: effects on muscle strength, muscle quality, and physical function. Kidney Int. 2003;63(1):291297; doi: 10.1046/j.1523-1755.2003.00704.x.

27. Jamal SA, Leiter RE, Jassal V, Hamilton CJ, Bauer DC. Impaired muscle strength is associated with fractures in hemodialysis patients. Osteoporos Int. 2006;17(9): 1390-1397; doi: 10.1007/s00198-006-0133-y.

28. Spindler A, Paz S, Berman A, Lucero E, Contino N, Peñalba $A$, et al. Muscular strength and bone mineral density in haemodialysis patients. Nephrol Dial Transplant. 1997;12(1):128-132; doi: 10.1093/ndt/12.1.128.

29. Floyd M, Ayyar DR, Barwick DD, Hudgson P, Weightman D. Myopathy in chronic renal failure. Q J Med. 1974;43(4):509-524; doi: 10.1093/oxfordjournals.qjmed. a067402.

30. Nelson ME, Fiatarone MA, Morganti CM, Trice I, Greenberg RA, Evans WJ. Effects of high-intensity strength training on multiple risk factors for osteoporotic fractures. A randomized controlled trial. JAMA. 1994;272(24): 1909-1914; doi: 10.1001/jama.1994.03520240037038.

31. Stenvinkel $P$, Heimbürger $O$, Lindholm B, Kaysen GA Bergström J. Are there two types of malnutrition in chronic renal failure? Evidence for relationships between malnutrition, inflammation and atherosclerosis (MIA syndrome). Nephrol Dial Transplant. 2000;15(7):953-960; doi: 10.1093/ndt/15.7.953. 